\title{
Do self-interested learners avoid prosocial learning?
}

Benjamin Heslop benjamin.heslop@uon.edu.au ${ }^{1}$

Elizabeth Stojanovski elizabeth.stojanovski@newcastle.edu.au ${ }^{2}$

Jonathan Paul jonathan.paul@newcastle.edu.au ${ }^{1}$

Kylie Bailey kylie.bailey@newcastle.edu.au ${ }^{1}$

${ }^{1}$ School of Medicine and Public Health, Faculty of Health and Medicine

${ }^{2}$ School of Mathematical and Physical Sciences, Faculty of Science

University of Newcastle, Callaghan Campus

University Drive

Callaghan, NSW 2308

Australia

Correspondence to Benjamin Heslop 


\begin{abstract}
This article assumes that collaborators who adopt a positive-sum, prosocial perspective can build trust-based relationships, which is equivalent to collaborative ability (CA). To improve a collaborator's CA, we anticipated that content based upon a model of positive-sum collaboration, founded upon ancestral behaviours presented as social norms, might alter a zero-sum, proself, collaborator's perspective. However, we also postulated that learner's willingness to engage in positive-sum content may rely on pre-existing prosociality. Intervention participant's prosociality was assessed via self-assessment of their emotional intelligence (EQ), quality of life (QoL), and goal orientation (GO). Learner's engagement in online content was assessed by the three stage reached: examine website front matter; examine website content; learn website content. Tukey's multiple comparison showed a statistically significant difference between stages one and three, in the mean of respondent's self-assessed QoL. This suggests that participants who wished to learn content had, on average, higher quality of life, and potentially therefore greater prosociality. In general, these findings support a claim that any intervention designed to increase individual prosociality may need to consider the target population's reticence to engage.
\end{abstract}

Keywords: collaboration, social norms theory, emotional intelligence, quality of life, goal orientation, prosocial, internet education 


\section{Do self-interested learners avoid prosocial learning?}

\section{Positive-sum Collaboration Skills}

Collaboration delivers benefits through interdependence-based synergies (Kumar, 2010), permitted by trust-based relationships. Competent collaborators recognise that trust-based relationships are built through positive-sum benefits, originating from win-win situations, such as achieving a team objective (Kloak, 2017). One way a collaborating partner can undermine trust is actively seeking personal advantage at colleague's cost, such as undue credit, status, money, power; and other zero-sum benefits (Rusbult \& Van Lange, 2003). Conversely, an example of a passive zero-sum approach is free riding, where a team member limits their contribution while maintaining an equal allocation of benefits, for instance, equal marks for a group project (Rusbult \& Van Lange, 2003). Social exchange theory contends that selfish, trusteroding, behaviour is more likely when the benefit is exclusive or rare; and therefore zero-sum by definition (Cropanzano, Anthony, Daniels, \& Hall, 2017). Hence, humans have an inbuilt tendency to cease collaboration when sufficiently tempted by a desirable outcome.

Game theory laboratory experiments show that trust is diminished when a partner exhibits selfishness by taking a zero-sum, or proself, option, when a positive-sum, or prosocial, option was also available (Neumann \& Morgenstern, 1944). Nevertheless, because game theory rewards for positive-sum behaviour are typically financial, we consider these experiments may not accurately simulate collaboration. Being finitely-divisible; and therefore zero-sum, we expect that financial rewards will prompt players to act selfishly (Scodel, 1962). This tendency will likely vary depending upon cultural attitudes toward positive- versus zero-sum behaviours. For instance, members of some remnant hunter-gatherer societies became angry when a Western partner made a positive-sum choice (Henrich et al., 2005). These tribes had a cultural expectation 
that any generous gesture implied the receiver had less wealth and status. In these societies, any favour bestowed was thereupon resented by the receiver as an indication of their lower status.

Conversely, tribes that routinely traded with other tribes were more willing to accept a positive-sum offer. Trade is a positive-sum activity, since it relies upon specialisation in production that reduces overall production costs (C. W. L. Hill, 1990). In general, this suggests that culture, and individuals, can vary in their expectations of zero- versus positive-sum behaviour, based upon their historical experience. Those who had predominately zero-sum interactions during their formative years, for instance, being routinely taken advantage of by those with greater power, may not have the capacity to recognise, or value, positive-sum collaboration. We postulate that demonstrating how collaboration is perceived by prosocial participants, will foster emulation in those with a zero-sum perspective.

\section{Persuading a Zero-sum Collaborator}

Demonstrable resonance between humanities' ancestry and positive-sum collaboration may help to explain the mechanism, and also persuade a zero-sum collaborator of its desirability. It is often argued, to good effect, that people are healthier and happier when acting in harmony with our anthropological past. For example, regarding changing health behaviour, people are drawn to the 'paleo diet' and '5-2 fasting.' More relevant to collaboration, the social capital perspective has found that trust-based relationships, characterised by stable friendships and longterm partners, predict mental health and longevity (Hawkley \& Cacioppo, 2010). However, the weakness of social capital is a focus on the societal level, and influences such as government policy and urban design, rather than individual perspectives, and ensuing behaviour. Nudge theory, by contrast, changes individual behaviour by persuading people that certain choices contravene social norms (Arno \& Thomas, 2016). 
We contend that a related approach is suggesting an evolutionary basis to collaboration, and in doing so, promoting positive-sum collaboration as an ancestral rather than a social norm (Wilson \& Wilson, 2007). A positive-sum perspective is both likely to attract a positive response from colleagues, and being 'natural,' also reflects ancestral behaviour (Boehm et al., 1993). The former corresponds to an injunctive norm, which Social Norms Theory (SNT) defines as attracting social praise or disapproval from one's peers (Cialdini, Reno, \& Kallgren, 1990). The latter 'natural/ancestral' basis corresponds to a descriptive norm, which is what people actually do, rather than in the case of an injunctive norm, what they approve of (Kenrick, Li, \& Butner, 2003). We consider that imparting both injunctive and descriptive norms is likely to be more effective than either in isolation.

\section{Ancestral Behaviours as Social Norms}

With the intent of improving a participant's behaviour, interventions using SNT communicate correct social norms, so that incorrect (or undesirable, in the case of injunctive norms) perceptions of peer's behaviour may be replaced (Berkowitz, 2005; Schultz, Nolan, Cialdini, Goldstein, \& Griskevicius, 2007a). One way that a participant may resist a SNT intervention is by discrediting any descriptive norm being imparted, specifically by identifying a perceived inaccuracy (Granfield, 2002). An in-person SNT intervention may have facilitators available to discuss participant's confusion over norms (Clapp, Lange, Russell, Shillington, \& Voas, 2003), however, an online SNT must follow a preventative strategy that minimises the opportunity for cherry-picked weaknesses, and therefore only include norms that participants will identify as accurate and relevant (Webb, Joseph, Yardley, \& Michie, 2010).

While SNT is typically applied to undesirable activities, such as smoking or alcohol consumption (Berkowitz, 2005), collaboration is not usually optional within a person's working 
life. Therefore, overreliance upon aspirational, injunctive norms may stray into unrealism, which risks the zero-sum member perceiving them to be irrelevant or inaccurate. While a positive-sum perspective can be framed as an injunctive norm likely to attract praise, within that perspective are various behaviours that are ideally couched as ancestral, descriptive norms that can claim to be realistic.

Avoiding perception of inaccuracy may require inclusion of norms that are selfinterested, which is also consistent with collaboration being adaptive for individuals (Kenrick et al., 2003). It is not adaptive to allow oneself to be taken advantage of by colleagues who are, for instance, adopting a zero-sum approach. Hence, norms related to collaboration should include those that prompt both pro-social and self-interested behaviours, while maintaining consistency with a positive-sum perspective.

Prosocial behaviours are intended to improve a collective outcome, whereas proself behaviours are intended to maximise one's absolute, or relative, benefit (Morrison, 2006). However, proself behaviour can be from a positive-sum perspective if helping oneself is not to colleagues' detriment, for instance, leaving a group that is likely to fail regardless. On the other hand, some behaviours can also appear zero-sum, while delivering a prosocial result. For example, dominating colleagues in an emergency situation featuring poor communication, yet requiring fast decision-making (David-Barrett \& Dunbar, 2013). Hence, the difference between zero- and positive-sum may not be the behaviour itself, but the extent to which the member has considered their colleagues' interests before acting. A positive-sum perspective attracts a member to win-win scenarios, while a zero-sum perspective is content with win-lose if that proffers the greatest personal advantage (Haroush \& Williams, 2015). 


\section{Perceptions of identity threat}

Including self-interested behaviours may also reduce potential for identity threat in those who explicitly self-identify as justifiably using a zero-sum perspective (Jetten, Postmes, \& McAuliffe, 2002). Identity threat is the feeling that one's in-group, or tribe, is being attacked because of what is being said or done to you. An example of an audience, for whom this intervention may invoke identity threat, are males who are accustomed to manipulating females into sex, for example 'negging' which aims to reduce confidence (Lilly, 2016). Another is those who strongly identify with race or nation, and who may feel that a positive-sum perspective threatens their justification to be racist or nationalist (Voci, 2006). By promoting self-interested behaviours as permissible, albeit under tightly-defined conditions, the zero-sum participant's sense of having their antipathy or selfishness condemned outright, leading to identity threat, is hopefully reduced.

Beyond a participant avoiding social norms that conflict with their tribe, a general reticence of a zero-sum participant to consider positive-behaviour may also be explained by matching law (Poling, Edwards, Weeden, \& Foster, 2011). This law has empirically found that animals and people create heuristics, the strength of which is mathematically predicted upon the relative size and likelihood of reward that had been received from past use of that strategy (Snyder, Stoolmiller, Patterson, \& Schrepferman, 2003). School-yard bullying suggests that zerosum behaviours can indeed be successful from the participant's perspective, if intimidation is considered success. More generally, for socially-disadvantaged areas where violence is common, zero-sum behaviours may be more successful than positive-sum due to the sparsity of potential collaborators who will recognise, and respond favourably to, positive-sum overtures (Knauft et al., 1991). Those who routinely display zero-sum behaviour may have historical reasons for 
continuing to do so, and change may therefore be resisted. We propose that even should positivesum norms be couched as ancestral and ubiquitously accessible, learners may refuse to question zero-sum heuristics or tribal, xenophobic identities. Therefore, based upon a potential for the boomerang effect, this intervention may find it easier to recruit participants who already hold a positive-sum perspective (Schultz, Nolan, Cialdini, Goldstein, \& Griskevicius, 2007b).

\section{Positive-sum model of collaboration}

The Encapsulated Unified Collaboration Research Model (EUCRM) is the model of collaboration taught within this intervention. Each of its components are positive-sum, in the sense that should the collaboration be viable, all team members can simultaneously perceive each component as high. Performance is the group's current success at accomplishing tasks, and continued prospects of doing so. Liking is one's perception of the cumulative strength of relationships between you and colleagues. Respect is one's estimation of colleagues' knowledge, skills and abilities (KSA), and their trustworthiness in applying them. Communication is the level of help and assistance that one is willing to render, or accept from, colleagues. Confidence is your one's to constructively suggest improvements to the group, or specific members.

\section{Hypotheses of Current Study}

This article describes a pilot study that offered an online intervention advertised as potentially improving participant's Collaborative Ability (CA). We postulated that zero-sum participants would be reticent to engage with the intervention content, but that should they do so, their perspective would become less zero-sum. Since admitting zero-sum selfishness carries significant social penalty in most societies, a zero-sum perspective is difficult to survey directly, due to respondent's desire for self-enhancement (Mathieu, Gilson, \& Ruddy, 2006). It was therefore hypothesised that zero-sum perspective could be indirectly self-assessed, for instance, 
by surveying; social awareness, worldview (glass half-full, or half-empty), and whether learning was more important than preserving one's reputation. The first perspective was measured via emotional intelligence, the second via quality of life, and the third via goal orientation.

\section{Emotional Intelligence}

We contend that emotional intelligence (EQ) is strongly related to CA, since it involves the ability to manage one's emotions, and to perceive emotions in others (Rego, Sousa, Pina Cunha, Correia, \& Saur-Amaral, 2007). As shown by Pradhan, Jena, Bhattacharya, \& Nisar (2016), EQ is correlated with positive-sum behaviours, such as organisational citizenship (Morrison, 1994). Consistent with a claim that positive-sum collaboration helps in life success, a meta-analysis of research where EQ is taught in school has shown improvements up to 18 years post-intervention, such as improvements in high school graduation rate, and lower sexual risktaking (Taylor, Oberle, Durlak, \& Weissberg, 2017). Because they find the positive-sum perspective familiar and accurate, we hypothesise that high EQ respondents will preferentially engage with the intervention.

H1a: Higher EQ is associated with initial engagement with the intervention.

\section{Quality of Life}

Quality of life (QoL) is a wide-ranging construct incorporating the four domains of physical health, psychological health, social relationships, and external environment (The WHOQOL Group, 1996). Just as for EQ, we anticipated that those who perceive they have high QoL will attempt the intervention due to a greater familiarity with a positive-sum perspective. In addition, those experiencing satisfactory QoL will also have lower levels of stress that enables learning of complex information, such as contained in the intervention (Routledge et al., 2016). 
Since, as previously noted, CA promotes life success through richer relationships and larger networks, we anticipate that these will become evident in a correlation between QoL and EQ. H2a: Higher QoL is associated with initial engagement with the intervention. H2b: A significant correlation exists between QoL and EQ.

\section{Goal Orientation}

Development of skills and knowledge through a learning goal orientation (GO) fosters experimentation and calculated risks (Dweck \& Leggett, 1988). Conversely, a performance goal orientation promotes display of accomplishments, but avoidance of situations where failure may damage one's reputation. Measuring a zero-sum perspective with goal orientation is controversial since, as demonstrated by their inclusion in EUCRM, both learning (communication) and reputation (respect plus liking) are positive-sum benefits of collaborating. However, we contend that a propensity to preserve reputation, rather than learn, is characteristic of zero-sum, since it presumes that colleagues will take advantage of any reputational damage to bolster their own status.

For that reason, the EUCRM respect component is assessment of colleagues' Knowledge, Skills and Abilities (KSA), rather than concern with one's own, which may become competition for status. Conversely, a learning goal orientation improves the actuality, rather than appearance, of one's KSA. If learning is achieved without detrimental effects to others, it is a win for the individual, and a win for the collaboration that has access to the new KSA. Since GO is consistent with a positive-sum perspective, we postulated that GO would predict engagement with the intervention; that additionally provides a learning opportunity. We also anticipated that GO would correlate with both EQ and QoL.

H3a: Higher GO is associated with initial engagement with the intervention. 
H3b: A significant correlation exists between QoL and EQ.

\section{Persistence with the Intervention}

EUCRM is designed as a universal model of collaboration, making its components and impacts universally known for those participants with strong CA. Therefore, while the intervention may initially attract interest from positive-sum participants, their persistence is unlikely. We postulated that persistence would be especially brief for those participants with a high GO, due to a lack of learning and novelty. Conversely, we postulated that persistence would endure for those participants who appreciated the positive-sum perspective, yet had poor CA. Unfortunately, such people are likely to be rare in a student cohort, for example, suffering from autism spectrum disorder (ASD), and were unlikely to be captured by this pilot study.

H4a: Participants would fall into one of three groups: those who complete a majority of the online course, those who complete very little, and those who do not register for the course (but complete the pre-intervention survey).

H4b: Participants that complete a majority of the intervention would have lower GO, EQ and QoL than the other two groups with minimal engagement.

\section{Study Method}

Over first and second semesters 2016, health, science, engineering and humanities undergraduate and postgraduate students from an Australian university campus were invited to participate in an online intervention, advertised as improving their collaboration skills (Figure 1). Participants first responded to the pre-intervention survey, then created a user login on the intervention website (www.eucrm.com.au). Once we received notification this had occurred, the participant was granted access to an online education course. Over a three-month period, we recorded how many modules within the intervention website completed by each participant. 
Participants are referred to as respondents when replying to survey instruments; as learners when learning content; and as users when interacting with website administration.

Advertising flyer to potential participants in online intervention

\section{LEARN TO COLLABORATE}

\section{Collaborative employees are in demand!! Need to improve your collaborative ability?}

- Learn strategies for real problems in teams.

- Learn how people think and respond in group situations.

- Includes experimental evidence and psychological theory.

- Thirteen online modules, pick those you need.

- Mobile-friendly.

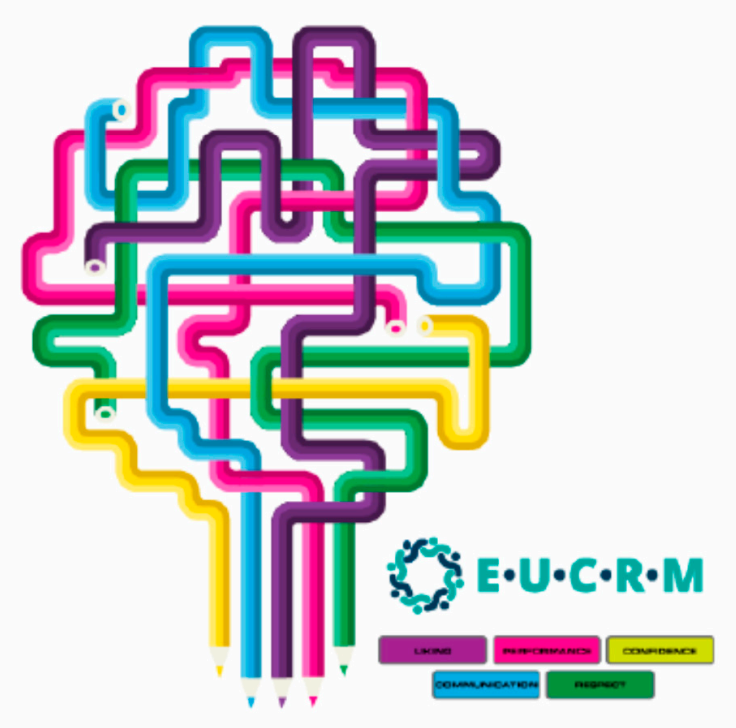

Figure 1.

\section{Intervention Website}

The online intervention, which consisted of learning modules within an online course, was implemented in Wordpress via the Academy theme. The theme was chosen for its functionality and user reviews (view at https://themeforest.net/user/themex). Wordpress was chosen because it is mature, cost-effective technology that affords some flexibility, and is ostensibly within the ability of a novice website developer (lead author). The intervention, 
delivered by the website, was comprised of 13 learning modules, the content of which was compiled from published articles, and demonstrating how their empirical findings supported EUCRM theory. Each module was designed to take 30 mins to complete, and were categorised as; beginner, intermediate, advanced and chimpanzee. Further details of the design of the online course can be found here (Heslop, Paul, Stojanovski, \& Bailey, 2017).

\section{Recruiting and Survey Pathways}

In the first semester an interface called SONA implemented all pre-intervention surveys, however, in second semester, all surveys were completed in Redcap. The pre-intervention survey collected demographic information and administered the instruments measuring EQ, QoL and GO. SONA recruited psychology undergraduate students in both semesters, while nonpsychology students were recruited through the primary author making a short presentation in their respective lecture. Redcap participants could create a username without completing the preintervention survey, but were excluded from this analysis.

\section{Three Stages of Engagement}

Based upon their level of engagement, participants were classified into one of four stages (Table 1). Stage one completed the pre-intervention survey only, and did not proceed to registering a EUCRM username. Stage two participants created a username, but did not complete a single module, while stage three completed at least one module.

Table 1

Three stages with increasing levels of engagement in the intervention

\begin{tabular}{llll}
\hline Stage & $\begin{array}{l}\text { Completed Pre- } \\
\text { intervention survey }\end{array}$ & $\begin{array}{l}\text { Created EUCRM } \\
\text { user }\end{array}$ & $\begin{array}{l}\text { Completed } \\
\geq 1 \text { Module }\end{array}$ \\
\hline One & $\mathrm{X}$ & & \\
Two & $\mathrm{X}$ & $\mathrm{X}$ & \\
Three & $\mathrm{X}$ & $\mathrm{X}$ & $\mathrm{X}$ \\
Four & $\mathrm{X}$ & $\mathrm{X}$ & $\mathrm{X}$ \\
\hline
\end{tabular}




\section{Instruments}

EQ was measured with the 16-item Wong and Law Emotional Intelligence Scale (WLEQS) (Law, Wong, \& Song, 2004) which comprised four subscales: self-emotions (1-4), other's-emotions (5-8), use of emotion (9-12) and regulation of emotion (13-16). WLEQS has been shown to have self-rating construct validity of $\alpha=.78$ and $\alpha=.89$ using multitraitmultimethod (MTMM) analyses compared against the Big Five personality traits, and workplace performance, respectively. Each question was scored between -2 to 2, giving a total score for each respondent between -32 and +32 .

QoL was measured with WHOQOL-BREF, a 26-item instrument based upon a 100 item instrument created by the World Health Organisation (The WHOQOL Group, 1996). WHOQOL uses a 5-item Likert scale to assess respondent's perception of QoL in four domains of; physical health, psychological health, social relationships, and external environment. WHOQOL has been validated for use in many nations, including Australia and New Zealand $(\alpha=.91)$ (Krägeloh et al., 2013). Each question was scored between 1 and 5, giving a potential total of between 26 and 130.

GO was measured using the instrument designed by VandeWalle (1997), which has three subscales; learning goal orientation (questions $1,2,3$ and $4: \alpha=.88$ ), prove orientation $(5,6,7$ and 8: $\alpha=0.84)$ and avoid orientation $(9,10,11,12$ and 13: $\alpha=.83)$. Total points from the $2^{\text {nd }}$ and $3^{\text {rd }}$ phases were subtracted from the $1^{\text {st }}$ phase, so a high total means presence of GO, but absence of prove and avoid orientations. Each question was scored between -2 to 2, giving a total for each respondent between -26 and +26 . 


\section{Results}

Pre-intervention survey results from respondents from each of three stages were collected. There were 101 participants in stage one, 45 in stage two, and 23 in stage three (Table 2). Of 169 responses to the pre-intervention survey that completed at least one of the primary instruments, 79 were via SONA in semester one, and 90 were via Redcap in semester two. Table 2

Demographics for each of three stages.

\begin{tabular}{|c|c|c|c|c|}
\hline \multicolumn{2}{|c|}{ Stage } & One & Two & Three \\
\hline & $\bar{n}$ & 100 & 45 & 23 \\
\hline Age & $\overline{\mathrm{x}}$ (S.D.) & $26.7(9.4)$ & $26.8(10.2)$ & $25.1(8.5)$ \\
\hline \multicolumn{2}{|c|}{ Male \% (n) } & $36.0(36)$ & $33.3(15)$ & $52.2(12)$ \\
\hline \multicolumn{2}{|c|}{ Australian national \% (n) } & $80.0(80)$ & $86.7(39)$ & $82.6(19)$ \\
\hline \multicolumn{2}{|c|}{ Romantically single \% (n) } & $15.0(15)$ & $22.2(10)$ & $8.7(2)$ \\
\hline \multicolumn{2}{|c|}{ Psychology student \% (n) } & $64.0(64)$ & $60.0(27)$ & $52.2(12)$ \\
\hline
\end{tabular}

\section{Demographics}

ANOVA demonstrated that the average age of each stage was not significantly different (Table 3). A Pearson Chi-square test of association comparing the proportions between stages for the remaining demographics also demonstrated no statistically significant differences in proportions between each pair of stages. Given psychology is female-dominated, it is not surprising that the gender ratio for each stage is consistent with the proportion of psychology students.

Table 3

Descriptive statistics for EQ, QoL and GO, for stages one, two and three.

\begin{tabular}{lllll}
\hline Stage & & One & Two & Three \\
\hline EQ & $\mathrm{n}$ & 96 & 45 & 23 \\
& $\overline{\mathrm{x}}$ & 12.36 & 12.64 & 14 \\
& s.d. & 8.81 & 8.19 & 7.85 \\
& SE & 0.90 & 1.26 & 1.64
\end{tabular}




\begin{tabular}{lllll}
\hline Stage & & One & Two & Three \\
\hline QoL & $\begin{array}{l}\text { Normally } \\
\text { distributed }\end{array}$ & Yes & Yes & Yes \\
& $\mathrm{n}$ & 94 & 45 & 23 \\
& $\overline{\mathrm{x}}$ & 95.93 & 101.1 & 104.1 \\
& s.d. & 16.37 & 9.90 & 9.57 \\
& SE & 1.69 & 1.48 & 2.00 \\
& Normally & No & Yes & Yes \\
& distributed & & & \\
\hline GO & $\mathrm{n}$ & 100 & 45 & 23 \\
& $\bar{x}$ & 4.06 & 4.56 & 5.30 \\
& S.d. & 6.22 & 6.65 & 7.46 \\
& SE & 0.62 & 1.00 & 1.56 \\
& Normally & Yes & Yes & Yes \\
& distributed & & & \\
\hline
\end{tabular}

Each stage contains unique participants. Numerousness of data varies for each instrument due to incomplete responses.

\section{Differences in stage means}

Tukey's multiple comparison could be applied between each stage as the response data for each instrument measuring GO, EQ and QoL was normally distributed. The exception was stage one QoL responses, which were not normally distributed. A squared term transformation was applied on all QoL responses within all three stages, which satisfied the normality condition.

The mean responses for QoL, EQ and GO were not statistically significantly different between each pair of stages at the 0.05 significance level, except for mean QoL which was significantly different between stages one and three (Figure 2) $(p=0.04)$.

Box and whisker plots for stages one, two and three for Quality of Life (QoL), Emotional Intelligence (EQ) and Learning Goal Orientation (GO). Differences were calculated between all stages $(1 \mathrm{v} 2,2 \mathrm{v} 3,3 \mathrm{v} 1)$ within each instrument. 

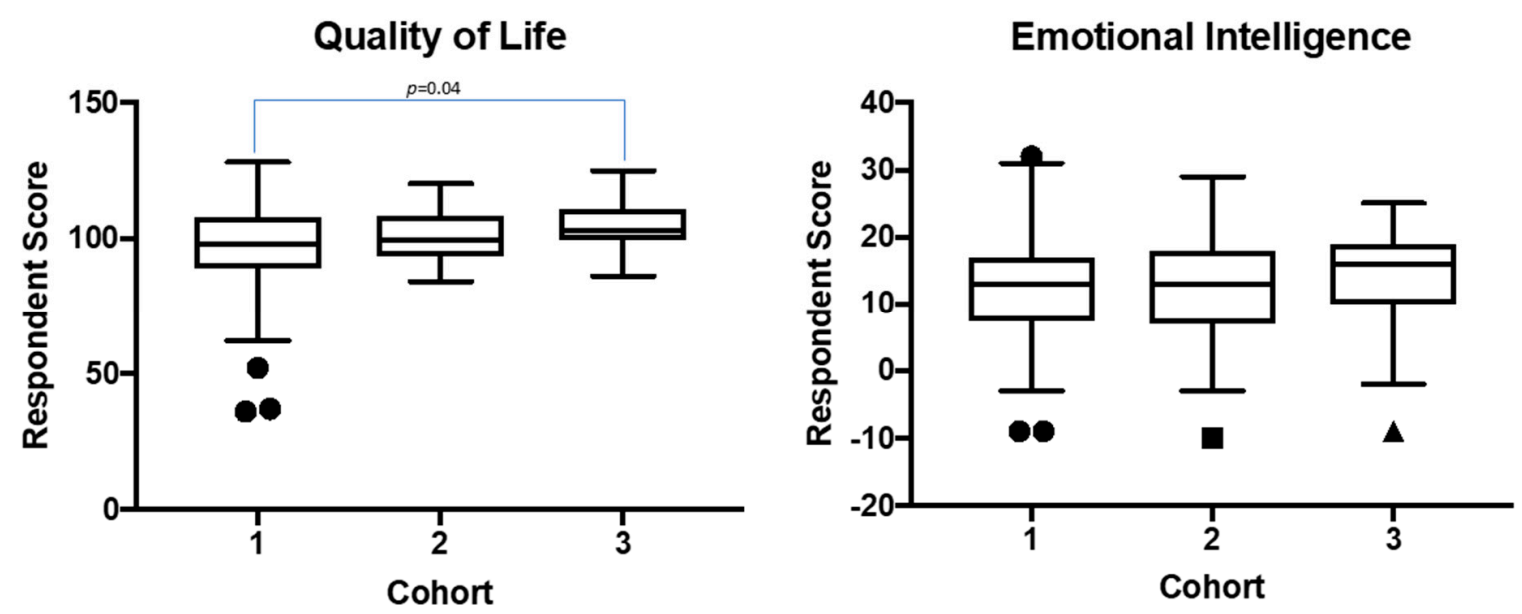

\section{Goal Orientation}

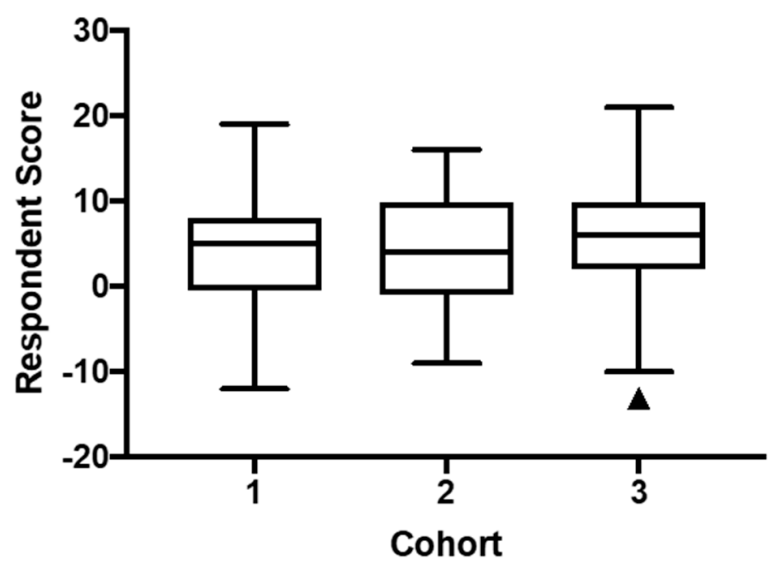

Figure 2.

\section{Correlations between Instruments}

Pearson correlation coefficients between QoL, GO and EQ showed a strong, significant correlation between QoL and EQ $(r=0.52, p<0.001)$, a weak correlation between EQ and GO $(r=0.17, p=0.027)$ and no significant correlation between QoL and GO $(r=0.12, p=0.124)$.

\section{Persistence with the Intervention}

We examined the rate of module completion for 23 stage three participants. Twenty-two learners completed only a minority of the online course, while one learner completed all 13 modules (Table 4). 
Table 4

Modules completed by learners in stage three

\begin{tabular}{ll}
\hline $\begin{array}{l}\text { Modules } \\
\text { completed }\end{array}$ & $\begin{array}{l}\text { Proportion of stage } \\
\text { three learners (n) }\end{array}$ \\
\hline 1 & $21.7 \%(5)$ \\
2 & $47.8 \%(11)$ \\
3 & $17.4 \%(4)$ \\
4 & $8.7 \%(2)$ \\
13 & $4.3 \%(1)$ \\
\hline
\end{tabular}

\section{Discussion}

The only significant difference was between stages one and three in QoL (Figure 2). Due to stage one not being normally distributed, a squared term transformation was applied. Tukey's multiple comparison of the transformed data found the difference to be statistically significant at the 0.05 level ( $p=0.04)$. The null hypothesis (H1a) the QoL does not predict engagement in the intervention can be rejected because QoL increases from stages one to three. The null hypotheses $(\mathrm{H} 2 \mathrm{a}, \mathrm{H} 3 \mathrm{a})$ that GO and EQ predict engagement cannot be rejected, however. As was hypothesised, when responses for QoL, EQ and GO were compared between stages, it was evident that the means increase from stage one to three. Considering that all differences in means are as hypothesised, we do not consider this result to be a random outcome due to there being nine comparisons conducted. These findings therefore provide limited support for the overarching hypothesis that participants with poor CA will avoid an intervention intended to improve them.

The central finding of this research is that those with poor CA may be less likely to voluntarily improve them. Consistent with social norms theory and self-regulation theory, we proposed that content drawn from a positive-sum perspective would be aversive to a zero-sum participant. Stage one participants may only have viewed the front content, but this is considered 
sufficient information to discontinue. Stage two participants, who registered, often viewed Aims and Methods pages of modules, but did not proceed to complete a comprehension quiz, which was requisite for stage three. While the effect size between stages was non-significant in all cases except one, stage means nonetheless proceeded in the anticipated direction. The single significant difference was between the means of QoL stage one (96) and three (104).

Unfortunately, due to its novelty, we are unable to compare these results against extant literature. There are no studies using SRT or SNT undertaken to improve CA, with a majority being to reduce undesirable campus behaviour such as misogyny or problem drinking. There are also no interventions that measure participant's willingness to engage, since randomised controlled trials place participants in treatments; withdrawal from which would be considered removal from the trial. Finally, there is no literature that intervenes through teaching social norms based upon ancestral instincts. At the time of writing, search on Google scholar for the phrases "ancestral social norms", "anthropological...", "adaptive...", and "evolutionary..." reveals a total of only 40 articles, none of which involve behaviour change. We therefore consider that improving CA, through teaching ancestral norms, is a novel approach, as is measuring the voluntary engagement of participant within a SNT-based intervention.

Correlation between QoL and EQ $(\mathrm{r}=0.52 * *)^{1}$ is largely consistent with extant literature, which surprisingly lacks a meta-analysis focusing on cross-sectional rather than longitudinal studies, where EI training is the intervention method. Of those individual studies that were identified, EQ and QoL for Taiwanese tour guides (Min, 2014) and Canadian teachers (Hsiang, 2016) correlate at $\mathrm{r}=0.55^{* *}$ and $\mathrm{r}=0.44^{* *}$ respectively. Conversely, Indian teachers report no

$$
1 * p<0.05, * * p<0.01
$$


correlation between EQ and QoL (Anjum \& Swathi, 2017). This discrepancy may be as a result of caste-based selection of Indian teachers (Deshpande, 2000), which may have reduced the postulated mechanism by which respondent EQ would affect their eventual QoL. Thus, India would seem a 'control group' for the postulate that, given a meritocratic society allowing the building of personal networks through sustained EQ, the result is better QoL.

Correlation between GO and EQ $\left(r=0.17^{*}\right)$ is consistent with literature, but there is also the lack of meta-analysis. Two studies show inconsistency among the three components of GO; learning $\left(\mathrm{r}=0.29^{* *}, \mathrm{r}=0.15^{\mathrm{ns}}\right)$, performance-prove $\left(\mathrm{r}=0.21^{*}\right)$ and performance-avoid goal orientations $\left(\mathrm{r}=-0.28^{* *}, \mathrm{r}=-0.11^{\mathrm{ns}}\right)$; and their correlations with EQ. Nevertheless, when these component correlations are additively combined as the GO instrument requires, our weak correlation is equivalent. A weak correlation between GO and EQ may indicate that their postulated alignment with a positive-sum perspective may be over-stated. For example, a person with strong EQ may employ it to manipulate their reputation, fulfilling the performance goal orientation, and lowering GO. Even when doing so, the intent may be positive-sum, if the motivation is intrinsic rather than extrinsic, since it seems unlikely to gain internal satisfaction from a reputation gained through diminishing others. Conversely, improving reputation to meet others' expectations may tend towards zero-sum, because others can be fooled if they are not aware of your role in diminishing the reputations of others.

As no similar research was found, the final correlation between $\mathrm{GO}$ and $\mathrm{QoL}\left(\mathrm{r}=0.12^{\mathrm{ns}}\right)$ was unable to be corroborated. Nevertheless, a lack of extant literature may itself be an indirect support for our non-significant finding, due to a well-established publication bias against it. The non-significant correlation suggests that a strategy of preserving reputation may eventually be as beneficial to QoL as a strategy based upon learning orientation. This is a reasonable given that, 
as suggested by the EUCRM respect component, maintaining one's reputation for competence and trustworthiness is a legitimate objective when collaborating. It is consistent with the preceding suggestion that GO may be a poor measure of a positive-sum perspective.

Regarding persistence with the intervention, there are too few participants to draw a conclusion. However, for 22 participants, the rate of module completion appears to form a normal distribution centred on two modules completed. The $23^{\text {rd }}$ participant completed all 13 modules, and is either an outlier, or the sole representative of the theorised second group. Given that our intent is eventually assisting populations with significant lack of CA, we hope that the latter is true. As it stands, only the two beginner modules were consistently viewed and completed. Those remaining received only little attention, making assessment of the intervention's efficacy difficult. This suggests that either the modules were intrinsically not interesting nor beneficial, or that those with a positive-sum perspective in stage three found it to be so. We note that there exists another, unmeasured, stage - those who did not engage in the intervention in any way, and may have had a stronger zero-sum perspective than stage one.

\section{Limitations}

Quality and quantity of the data were reduced by three unforeseen difficulties with software platforms, further details found here (Heslop et al., 2017). First, the SONA credit structure for psychology students discouraged or prevented their completing the follow-up survey, reducing feedback from psychology students. Second, some participants experienced difficulties gaining access to the content due to the interaction of Wordpress and their own email's security, which persisted throughout the intervention.

Thirdly, while SONA was hosted by the University of Newcastle School of Psychology, Redcap was hosted by the School of Medicine. SONA was designed to manage psychology 
student's mandatory participation in online interventions as part of their course requirements. Redcap was designed to run complex, longitudinal health interventions within the public, and offered features such as logical branching, longitudinal capability, automatic email reminders and no login process. A respondent logging in to Redcap only required a weblink to launch a unique survey instance, later designated by their email. By contrast, before sighting the EUCRM survey within SONA, non-psychology participants undertook multiple-step login process, followed by manual selection of the EUCRM survey from a list of eligible interventions. While psychology students had an existing login and were instructed within their course in navigating the SONA interface, for non-psychology students, SONA was onerous and perplexing. We created and placed on the EUCRM website a step-by-step guide for SONA, but it was not ready until later in semester one. By semester two, Redcap had been identified as superior for our application.

Please note that the original intent of this intervention was to ascertain effectiveness of EUCRM-based content in changing behaviour by gauging the difference between respondent's pre- and post-intervention scores of QOL, EQ and GO. However, there were too few participants for a statistically significant result, an analysis of which is a chapter within the lead author's doctoral dissertation (Heslop, 2018). We note that, after this intervention, EUCRM was superseded by the PILAR model, which conforms more closely to social psychology theory (Heslop et al., In press).

\section{Recommendations}

This research began with the postulate that those of a zero-sum perspective may improve their CA by adopting a positive-sum perspective. Three constructs were considered to indicate positive-sum and/or CA; emotional intelligence (EI), quality of life (QoL) and goal orientation (GO). Participant's EI and QoL were most correlated, and most conceptually aligned with, CA. 
GO was poorly or not at all correlated with EI and QoL respectively, perhaps indicating that a positive-sum perspective is not as strongly-linked to CA as we surmised. We are not aware of other research testing this postulate, and we recommend any future research to first identify (or develop) more reliable, fit-for-purpose, instruments to measure respondent's CA, and positivesum perspective. To avoid self-enhancement bias, or an incorrect perception of social norms, we recommend using peer-, rather than self-assessment, to measure both CA and positive-sum perspective.

The second part of the research attempted to establish that those with a zero-sum perspective were less likely to voluntarily engage in the intervention. Uniforms patterns in differences between stage means, admittedly only one of which was statistically significant, suggest this to be the case. Therefore, to gain the necessary numbers of zero-sum learners for a significant longitudinal change in behaviour, we recommend that recruitment be targetted at those with potential to improve. A population for future research may be high-functioning autistics, because they are adept with, and prefer, text-based content that offers clear rules (E. Hill \& Sally, 2004). By contrast, a school or prison population for example, may instead be treated with a method such as psychodrama, in which positive-sum behaviours are enacted in small groups under the guidance of a facilitator (Johnson \& Johnson, 2014). Whichever mode of delivery is chosen, to reduce evasion and resistance from participants, subterfuge may be required to avoid advertising the positive-sum content.

Partnership theory asserts that any community will either be governed by dominance or partnership modes of behaviour (Eisler, 1987). We have contended that breaking a potentially self-reinforcing cycle of zero-sum behaviour amongst a dominance-based cohort may encounter three types of resistance: social identity, social norms and matching law-based heuristics. Given 
the difficulty of this task, it may be necessary to mandate participants' positive-sum exposure. One low-cost option is accurate online instruction presenting ancestral norms (Heslop, Bailey, Paul, Drew, \& Smith, 2016).

\section{Conclusion}

This pilot study begins with cross-sectional examination of whether a positive-sum perspective predicts individual collaborative ability (CA). Our findings had two potential explanations: that goal orientation is a poor measure of positive-sum perspective, or that a positive-sum perspective has little relationship with CA, measured as emotional intelligence. The second, longitudinal, part of this research tests whether zero-sum participants will prefer to avoid the intervention, as suggested by social norms theory and self-regulation theory. We found some evidence that this was the case, which has implications for education-based interventions intending to change behaviour. It suggests that subterfuge, or enforced participation, may be required to provide target populations with sufficient information to overcome their resistance to participating due to wishing to avoid an unfamiliar or differing social norm.

Positive-sum versus zero-sum perspectives, and whether they influence social behaviours, and personal outcomes, are an understudied topic. It is nevertheless important to understand because it may damage collaboration by encouraging members to pursue self-interest, even when encouraged or taught otherwise, based upon their skepticism of the practicality of a positive-sum perspective. A model of collaboration such as EUCRM, constituted exclusively by positive-sum components, is a potential means of overcoming such skepticism, assuming the population can comprehend complex, text-based information. 
Compliance with Ethical Standards: Benjamin Heslop declares that he has no conflict of interest. Kylie Bailey declares she has no conflict of interest. Elizabeth Stojanovski declares that she has no conflict of interest. Jonathan Paul declares that he has no conflict of interest.

Ethical approval: All procedures performed in studies involving human participants were in accordance with the ethical standards of the institutional and/or national research committee and with the 1964 Helsinki declaration and its later amendments or comparable ethical standards. Approval to conduct this research was granted by the University Ethics Committee (H-20150360).

Informed consent: Informed consent was obtained from all individual participants included in the study 


\section{References}

Anjum, A., \& Swathi, P. (2017). A Study on the Impact of Emotional Intelligence on Quality of Life among Secondary School Teachers. International Journal of Psychology and Counseling, 7(1), 1-13. Retrieved from https://www.ripublication.com/ijpc17/ijpcv7n1_01.pdf

Arno, A., \& Thomas, S. (2016). The efficacy of nudge theory strategies in influencing adult dietary behaviour: a systematic review and meta-analysis. BMC Public Health, 16(1), 676. https://doi.org/10.1186/s12889-016-3272-x

Berkowitz, A. (2005). An overview of the social norms approach. In Changing the Culture of College Drinking: A Socially Situated Prevention Campaign (pp. 1-29). Hampton Press. Retrieved from http://alanberkowitz.com/articles/social norms approach-short.pdf Boehm, C., Barclay, H. B., Dentan, R. K., Dupre, M., Hill, J. D., Kent, S., ... Rayner, S. (1993). Egalitarian Behavior and Reverse Dominance. Current Anthropology, 34(3), 227-254. Retrieved from http://www.jstor.org/stable/2743665

Cialdini, R. B., Reno, R. R., \& Kallgren, C. A. (1990). A focus theory of normative conduct: Recycling the concept of norms to reduce littering in public places. Journal of Personality and Social Psychology, 58(6), 1015-1026. https://doi.org/10.1037/0022-3514.58.6.1015

Clapp, J., Lange, J., Russell, C., Shillington, A., \& Voas, R. (2003). A Failed Norms Social Marketing Campaign. Journal of Studies on Alcohol, 64(3), 409-414.

Cropanzano, R., Anthony, E. L., Daniels, S. R., \& Hall, A. V. (2017). Social Exchange Theory: A Critical Review with Theoretical Remedies. Academy of Management Annals, 11(1), 479516. https://doi.org/10.5465/annals.2015.0099

David-Barrett, T., \& Dunbar, R. I. M. (2013). Social elites can emerge naturally when interaction 
in networks is restricted. Behavioral Ecology, 25(1), 58-68.

https://doi.org/10.1093/beheco/art085

Deshpande, A. (2000). Does caste still define disparity? A look at inequality in Kerala, India. American Economic Review, 90(2), 322-325. https://doi.org/10.1257/aer.90.2.322

Dweck, C. S., \& Leggett, E. L. (1988). A social-cognitive approach to motivation and personality. Psychological Review, 95(2), 256-273. https://doi.org/10.1037/0033295X.95.2.256

Eisler, R. (1987). The Chalice and the Blade. San Francisco: Harper Collins.

Granfield, R. (2002). Can You Believe it?: Assessing the Credibility of a Social Norms Campaign, 1-8. Retrieved from http://socialnorms.org/wpcontent/uploads/2015/05/WP2.pdf

Haroush, K., \& Williams, Z. M. (2015). Neuronal Prediction of Opponent's Behavior during Cooperative Social Interchange in Primates. Cell, 160(6), 1233-1245. https://doi.org/10.1016/j.cell.2015.01.045

Hawkley, L. C., \& Cacioppo, J. T. (2010). Loneliness matters: a theoretical and empirical review of consequences and mechanisms. Annals of Behavioral Medicine : A Publication of the Society of Behavioral Medicine, 40(2), 218-27. https://doi.org/10.1007/s12160-010-9210-8

Heslop, B. (2018). PILAR: Proposed Systemic Model of Collaboration (Unpublished doctoral dissertation). University of Newcastle, Newcastle, Australia.

Heslop, B., Bailey, K., Drew, A., Paul, J., Stojanovski, E., \& Smith, R. (n.d.). Encapsulating Social Psychology: The PILAR Model of Collaboration. Review of General Psychology.

Heslop, B., Bailey, K., Paul, J., Drew, A., \& Smith, R. (2016). Collaboration Guidelines to Transform Culture. Interdisciplinary Journal of Partnership Studies, 3(3). 
Heslop, B., Paul, J., Stojanovski, E., \& Bailey, K. (2017). A Template for Online Training using a Theoretical Scaffold substantiated by Distilled Research. Manuscript Submitted for Publication.

Hill, C. W. L. (1990). Cooperation, Opportunism, and the Invisible Hand: Implications for Transaction Cost Theory. Academy of Management Review, 15(3), 500-513. https://doi.org/10.5465/AMR.1990.4309111

Hill, E., \& Sally, D. (2004). Dilemmas and bargains: Autism, theory of mind, cooperation and fairness. University College London.[aJH, ML], 44(0), 1-74. Retrieved from http://faculty.som.yale.edu/keithchen/negot. papers/Autism and Bargaining03.pdf

Hsiang, R. (2016). Teachers 'Mental Health: The Relevance of Emotional Intelligence in Burnout and Quality of Life. The University of Western Ontario.

Jetten, J., Postmes, T., \& McAuliffe, B. J. (2002). “We"re all individuals': Group norms of individualism and collectivism, levels of identification and identity threat. European Journal of Social Psychology, 32(2), 189-207. https://doi.org/10.1002/ejsp.65

Johnson, D., \& Johnson, F. (2014). Joining together: Group theory and group skills (11th ed.). Harlow, Essex: Prentice-Hall. https://doi.org/10.1037/014685

Kenrick, D. T., Li, N. P., \& Butner, J. (2003). Dynamical evolutionary psychology: Individual decision rules and emergent social norms. Psychological Review, 110(1), 3-28. https://doi.org/10.1037/0033-295X.110.1.3

Kloak, D. G. (2017). Strong Emotive Connectors: A Study of a Social Skill and Effective Team Performance. Alliant International University.

Knauft, B. M., Abler, T. S., Betzig, L., Boehm, C., Knox, R., Kiefer, T. M., ... Rodseth, L. (1991). Violence and Sociality in Human Evolution. Current Anthropology, 32(4), 391-428. 
Retrieved from

http://www.jstor.org/stable/pdfplus/2743815.pdf?\&acceptTC=true\&jpdConfirm=true

Krägeloh, C. U., Kersten, P., Rex Billington, D., Hsu, P. H. C., Shepherd, D., Landon, J., \& Feng, X. J. (2013). Validation of the WHOQOL-BREF quality of life questionnaire for general use in New Zealand: Confirmatory factor analysis and Rasch analysis. Quality of Life Research, 22(6), 1451-1457. https://doi.org/10.1007/s11136-012-0265-9

Kumar, S. (2010). Are joint ventures positive sum games? The relative effects of cooperative and noncooperative behavior. Strategic Management Journal, 32, 32-54.

Law, K. S., Wong, C.-S., \& Song, L. J. (2004). The construct and criterion validity of emotional intelligence and its potential utility for management studies. The Journal of Applied Psychology, 89(3), 483-496. https://doi.org/10.1037/0021-9010.89.3.483

Lilly, M. (2016). "The World is Not a Safe Place for Men": The Representational Politics of the Manosphere. University of Ottawa. Retrieved from https://www.ruor.uottawa.ca/bitstream/10393/35055/1/Lilly_Mary_2016_thesis.pdf

Mathieu, J. E., Gilson, L. L., \& Ruddy, T. M. (2006). Empowerment and team effectiveness: an empirical test of an integrated model. The Journal of Applied Psychology, 91(1), 97-108. https://doi.org/10.1037/0021-9010.91.1.97

Min, J. (2014). The Relationships Between Emotional Intelligence, Job Stress, and Quality of Life Among Tour Guides. Asia Pacific Journal of Tourism Research, 19(10), 1170-1190. https://doi.org/10.1080/10941665.2013.839459

Morrison, E. (1994). Role definitions and organizational citizenship behavior: The importance of the employee's perspective. Academy of Management Journal, 37(6), 1543-1567. Retrieved from http://amj.aom.org/content/37/6/1543.short 
Morrison, E. W. (2006). Doing the Job Well: An Investigation of Pro-Social Rule Breaking. Journal of Management, 32(1), 5-28. https://doi.org/10.1177/0149206305277790

Neumann, J. von, \& Morgenstern, O. (1944). Theory of games and economic behaviour. Princeton University Press. https://doi.org/10.1177/0883073816689647

Poling, A., Edwards, T. L., Weeden, M. A., \& Foster, T. M. (2011). The Matching Law. The Psychological Record, 61(1993), 313-322. https://doi.org/https://doi.org/10.1007/BF03395762

Pradhan, R. K., Jena, L. K., Bhattacharya, P., \& Nisar, T. (2016). Impact of psychological capital on organizational citizenship behavior: Moderating role of emotional intelligence. Cogent Business \& Management, 3(1), 1194174. https://doi.org/10.1080/23311975.2016.1194174

Rego, A., Sousa, F., Pina Cunha, M., Correia, A., \& Saur-Amaral, I. (2007). Leader SelfReported Emotional Intelligence and Perceived Employee Creativity: An Exploratory Study. Creativity and Innovation Management, 16(3), 250-264. https://doi.org/10.1111/j.14678691.2007.00435.x

Routledge, K. M., Burton, K. L. O., Williams, L. M., Harris, A., Schofield, P. R., Clark, C. R., \& Gatt, J. M. (2016). The shared and unique genetic relationship between mental well-being, depression and anxiety symptoms and cognitive function in healthy twins. Cognition and Emotion, 1-15. https://doi.org/10.1080/02699931.2016.1232242

Rusbult, C. E., \& Van Lange, P. a M. (2003). Interdependence, interaction, and relationships. Annual Review of Psychology, 54, 351-75. https://doi.org/10.1146/annurev.psych.54.101601.145059

Schultz, P. W., Nolan, J. M., Cialdini, R. B., Goldstein, N. J., \& Griskevicius, V. (2007a). Destructive, and Reconstructive Power of Social Norms. Psychological Science, 18(5), 
429-434. https://doi.org/10.1111/j.1467-9280.2007.01917.x

Schultz, P. W., Nolan, J. M., Cialdini, R. B., Goldstein, N. J., \& Griskevicius, V. (2007b).

Research Article: The Constructive, Destructive, and Reconstructive Power of Social Norms. Psychological Science, 18(5), 429. https://doi.org/10.1111/j.14679280.2007.01917.x

Scodel, A. (1962). Induced collaboration in some non-zero-sum games. Journal of Conflict Resolution, 6(4), 335-340.

Snyder, J., Stoolmiller, M., Patterson, G. R., \& Schrepferman, L. (2003). The Application of Response Allocation Matching to Understanding Risk Mechanisms in Development. The Behavior Analyst Today, 4(4), 335-345.

Taylor, R. D., Oberle, E., Durlak, J. A., \& Weissberg, R. P. (2017). Promoting Positive Youth Development Through School-Based Social and Emotional Learning Interventions: A MetaAnalysis of Follow-Up Effects. Child Development, 88(4), 1156-1171. https://doi.org/10.1111/cdev.12864

The WHOQOL Group. (1996). Whoqol-Bref: Introduction, Administration, Scoring and Generic Version of the Assessment. Programme on Mental Health. https://doi.org/10.1037/t01408000

VandeWalle, D. (1997). Development and validation of a work domain goal orientation instrument. Educational and Psychological Measurement. Retrieved from http://epm.sagepub.com/content/57/6/995.short

Voci, A. (2006). The link between identification and in-group favouritism: Effects of threat to social identity and trust-related emotions. British Journal of Social Psychology, 45(2), 265284. https://doi.org/10.1348/014466605X52245 
Webb, T. L., Joseph, J., Yardley, L., \& Michie, S. (2010). Using the internet to promote health behavior change: a systematic review and meta-analysis of the impact of theoretical basis, use of behavior change techniques, and mode of delivery on efficacy. Journal of Medical Internet Research, 12(1), 1-18. https://doi.org/10.2196/jmir.1376

Wilson, D. S., \& Wilson, E. O. (2007). Rethinking the Theoretical Foundation of Sociobiology. Quarterly Review of Biology, 82(4), 1-57. 